\title{
MENHIRES, KOLLONES Y ORÁCULOS DE GRANITO DE LA CUENCA LÁCAR, PATAGONIA NOROCCIDENTAL ARGENTINA
}

\author{
MENHIRS, KOLLONES (MASKSI AND GRANITE ORACLES IN \\ THE LÁCAR BASIN, NORTHWESTERN ARGENTINIAN PATAGONIA
}

Alberto E. Pérez ${ }^{A}$

En este artículo se describen y analizan, a partir de fuentes actualísticas etnográficas y etnohistóricas, novedosos artefactos, ecofactos y estructuras de granito cuya funcionalidad responde a la materialización de aspectos ideacionales de la sociedad mapuche de la cuenca Lácar durante los siglos XIX y xx. Su caracterización permite identificar y proyectar retrospectivamente el paisaje y los recursos existentes, así como distintas prácticas y formas de interacción de los habitantes de este territorio, más allá de los aspectos económicos y de subsistencia que han predominado tradicionalmente en los estudios arqueológicos de la Patagonia.

Palabras clave: Menhires, Kollones, Oráculos, Granito, Arqueología de la Patagonia.

From actualistic ethnographic and ethnohistorical sources, this article analyses novel artifacts, ecofacts, and granite structures whose functionality is associated with the materialization of the ideational aspects of the mapuche society in the Lácar basin in the 19th and 20th centuries. The current and historical characterization of these artifacts allows to identify and give a retrospective view of the landscape, its resources, and the different practices and forms of interaction of the inhabitants of this territory, beyond the economic and subsistence aspects that have traditionally predominated in the archaeological studies of Patagonia.

Keywords: Standing Stones/Menhirs, Masks, Oracles, Granite, Archaeology of Patagonia.

\section{INTRODUCCIÓN}

Entre las décadas de 1920 y 1950, los etnógrafos Bertha Koessler-Ilg y Wily Hassler dieron a conocer la presencia de rocas que eran parte de los oráculos durante prácticas rituales en distintos contextos ceremoniales de la cuenca Lácar (fig. 1). Al igual que otros etnógrafos de la Patagonia del siglo xx, como Martín Gusinde, junto a los selknam de Tierra del Fuego, y Esther Hilger con los mapuches en Panguipulli, Bertha Koessler-Ilg es integrada a la comunidad mapuche local con el estatus de reche (gente pura), al ser considerada nieta adoptiva del cacique Kollupan. Así accede a información que usualmente es revelada mediante el acompañamiento, la tutela o el uso de piedras sagradas utilizadas como bancos. Tres de ellas fueron trasladadas desde diversos espacios ceremoniales de la cuenca Lácar (Departamento Lácar, Provincia de Neuquén) a la residencia de la etnógrafa, conformando un oráculo desde el cual los especialistas recitaban información en idioma chezungun, siendo traducida in situ a Koessler-Ilg.

Tanto en Europa como en el mundo andino de América (Curatola 2011), un oráculo está compuesto de

\footnotetext{
A Alberto E. Pérez, Departamento de Antropología, Universidad Católica de Temuco, Chile. Orcid: 0000-0001-7287-6405. E-mail: aperez@uct.cl
} 
entidades materiales e inmateriales que operan en forma concurrente para comunicar el mundo terrenal con el espiritual o sobrenatural, lo que requiere la intervención de especialistas que puedan interpretar sueños, señales físicas, artefactos, símbolos, sacrificios, entre otros $(\mathrm{Cu}-$ ratola \& Ziólkowski 2008, Curatola 2011). También hay presencia de oráculos para el nütran o conocimiento mapuche (Foerster 1985, Schindler \& Schindler-Yáñez 2006, Skewes \& Guerra 2016, Menard 2018), ya que por extensión se llama oráculo al propio lugar donde se hacen consultas y se reciben las respuestas. Tal es el caso de los nguillatue, que incluyen distintos artefactos, ecofactos y estructuras dentro de espacios diseñados para la interacción entre seres humanos, deidades y antepasados bajo la conducción de líderes espirituales. Bertha Koessler-Ilg se refiere a pentufe como "oráculo" y a peutun como el acto de consultar y predecir a partir de elementos y señales de la naturaleza (Koessler-Ilg 1963: 80, 81 y 96 ).

Por último, hay registros etnohistóricos de la existencia de oráculos que se forman y materializan a partir de actos colectivos, en los que diversos participantes se agrupan generando espacios o lugares acotados que funcionan como portales, desde los cuales quienes dirigen el ritual -machis y kalkus- interactúan con entidades sobrenaturales (Latcham 1924, Treutler 1859).

...y a ellos van otros muchos indios con presentes, para que les profeticen cosas que desean saber, y ellos los traen engañados con mil embustes y falsas respuestas, como engañosos oráculos (Rosales, en Toribio Medina 1952: 246).

\section{En la cuenca Lácar}

A comienzos de la segunda mitad del siglo xx, ya fallecidos los portadores de las piedras sagradas que conformaban el oráculo y la etnógrafa Bertha Koessler-Ilg, la nueva generación de líderes político/religiosos de la cuenca Lácar exclama: “Tenemos que recuperar la 'piedra imán', que da fuerza a la raza, porque está en ella el espíritu de los antepasados" (Gregorio Curruhuinca, en Hassler 1963, vol. I, p. 52).

Fue el mismo longko Gregorio Curruhuinca quien manifestó que las piedras sagradas solían ser transportadas a diferentes espacios ceremoniales; sin embargo, desde la década de 1960 se desconoció su paradero (Hassler 1963). Tanto Curruhuinca como varios de sus sucesores atribuyeron la ausencia de estas a una "pérdida de eficacia" en las invocaciones durante las ceremonias rituales realizadas en las décadas posteriores en la cuenca.

\section{OBJETIVOS}

Mediante la descripción y análisis contextual nos proponemos: 1) caracterizar un espacio ceremonial reconocido como oráculo; 2) identificar las rocas/bancos como un grupo morfológico/funcional, señalando atributos que puedan ser asumidos como artefactos y ecofactos arqueológicos; 3) discutir la posible vinculación de otras rocas registradas por nosotros en diversos sitios arqueológicos de la cuenca Lácar con este singular grupo morfológico/funcional o tipológico.

\section{ASPECTOS TEÓRICOS Y METODOLÓGICOS}

En las cosmovisiones amerindias, el mundo físico es concebido como una entidad viviente (Saunders 2004, Hermo 2008), donde incluso los minerales son parte integral de entidades mayores, como montañas, volcanes, lagos y valles, los que, a través de la mitología, retienen parte de la importancia otorgada a características de los paisajes (Saunders 2004: 137, Hermo 2008: 320). Los sujetos mantienen relaciones rituales, de tipo comunitario o genealógico, con dichas entidades (Bonomo 2006). La materialización, visibilización y representación de ancestros y seres míticos logran tener lugar mediante su litificación (Galdames 1987, Rubina 1992, Moulian \& Espinosa 2014). La presencia espiritual que adquieren ciertas rocas producto de esta litomorfosis, ampliamente difundida en el mundo andino (Duviols 1973, Galdames 1987), está presente en la sociedad mapuche (Cañas 1909).

\footnotetext{
...jamás un indio dejará de mirar con respeto supersticioso a una piedra huitranche. Si la ve solitaria al borde de su camino, le hará el homenaje que la tradición ha establecido. La saludará dando una vuelta a su alrededor, le dejará alguna ofrenda y le pedirá de viva voz o in mente, que intervenga ante los malos espíritus para que no le hagan sufrir peripecias en su camino. Es que los considera guardianes de la montaña que suelen castigar las profanaciones que, según los ritos autóctonos, son delitos que tarde o temprano se pagan con una muerte violenta (Gregorio Álvarez 1984: 87).
}

En el alegato del cacique Chacayal contra Francisco Pascasio Moreno durante el parlamento de Quemquen- 
treu en 1876 -que culminó con su malograda condena a muerte por brujería-, los relatos de testigos refieren a Bertha Koessler-Ilg en la década de 1920:

\begin{abstract}
Un chelkura, un hombre de piedra, cayó de la planicie alta, donde había estado siempre el santo hombre de piedra, importante en las fiestas religiosas de abajo. Lo encontraron más tarde en el río, pero estropeado. La parte de arriba, la cabeza, nunca se encontró. ¿Cuándo hubo antes una desgracia tan grande en la tribu?, ¿cómo puede este ser creado por el Grande del cielo, andar de noche sin cabeza; ese, que no hace daño, que siempre ha sido piedra?, ¿cómo va a vivir sin cabeza? Mucho mal ha traído este uinka (alegato de Cacique Chacayal en 1876, en Koessler-Ilg 1962: 218-225).
\end{abstract}

En este contexto, los objetos naturales adquieren valores culturales en virtud de su origen en sectores del paisaje animados por estas fuerzas y seres míticos (Hermo 2008), considerados antepasados de los miembros de cada unidad totémica (Radcliffe-Brown 1973, LéviStrauss 1982, Ingold 2000, Bonomo 2006: 91). Esto se debe a que, en ocasiones, estas fuerzas vitales, energías y poderes pueden ser transmitidas a los artefactos e incluso a las personas a través del manejo de esta "sinergia mítica”, por medio de prácticas rituales (Saunders 1999, Jones \& MacGregor 2002, Hermo 2008). En la sociedad mapuche, esta fuerza-energía-poder o newen y la vitalidad o mogen (sensu Menard 2018) pueden estar presentes indistintamente en todo elemento de la naturaleza. En otro trabajo, sobre la base de mis propias experiencias etnográficas entre las comunidades de Nueva Imperial y Carahue, durante 2017 y 2018, he integrado newen y mogen denominándolos "fuerza vital” (Pérez et al. 2019). Los artefactos (aquellos que requieren ser modificados/elaborados para su uso o función); los ecofactos (material natural u objetos transportables que no requieren modificación para su uso o función), así como estructuras (compuestas por artefactos o ecofactos funcionalmente complementarios y no transportables), espacios, paisajes, árboles, orificios u oquedades e incluso formaciones rocosas (no transportables) cargadas de esta fuerza vital pueden, mediante la interacción por parte de especialistas en actos rituales, tender puentes entre las diversas dimensiones del universo mapuche (Faron 1997, Foerster 1985, Moulian \& Espinosa 2014, Skewes \& Guerra 2016, Menard 2018).

$\mathrm{Al}$ igual que en el área centro-sur de Chile (Menard 2018, Campbell et al. 2020), en la Patagonia noroccidental de Argentina también se cuenta con registros de cuevas, lagos y rocas que actúan como portales en los procesos de ancestralización (sensu Taylor 1987, 2000: 647). Aquí nos centraremos en los registros de la cuenca Lácar y sus alrededores, donde muchas rocas llamadas kura huitranche, huitrankuras (Álvarez 1984) y chelkuras (Koessler-Ilg 1962) fueron antes hombres, los que, convertidos en piedra, siguen en pie como vigías y figuras protectoras de los linajes (Álvarez 1984: 68). Desde la segunda mitad del siglo xIX contamos también con registros de uso de rocas transportables como amuletos en la cuenca Lácar, por ejemplo, las "piedras rayo". Se trata de hachas líticas que Ngenechen envía desde el cielo a lo profundo de la tierra mediante rayos. Estas emergen luego lentamente y traen protección a quien las encuentre y a su familia, además de un poder sobrenatural -principalmente curativo- a quien se especialice en la interacción con las fuerzas de la naturaleza, como machis y kalkus, o tenga facultades delegadas por el colectivo, como los lukutuhe, nguillatufe, entre otros (Koessler-Ilg 1962, Faron 1997, Moreno 2010, Pérez et al. 2019). Dichas hachas han sido mencionadas también para el sector occidental cordillerano (Menard 2018).

\section{Oráculos como espacios de comunicación e interacción}

La palabra "oráculo" deriva del latín oraculum, que significa "orar", "rezar", "rogar" o también "hablar", "decir en público". En distintos idiomas modernos como el español -oráculo-, italiano -oreacolo-, alemán -Orakel-, inglés -oracle- (Curatola 2011), es un término aplicable a sujetos muy diferentes, tales como divinidades, adivinos o santuarios, relacionados con el ámbito de la adivinación o las predicciones (Curatola 2011: 7). Sin embargo, en su terminología más clásica, el término presenta dos acepciones. Una de ellas, basada en estudios de la antigüedad clásica de autores como Herbert Parke (1967), alude a enunciados formales de parte de una divinidad a partir de una pregunta o consulta tanto por parte de un individuo (y de carácter personal) como también de una institución o colectivo, durante cuya práctica pueden desplegarse diferentes métodos e intervenir distintos objetos. La otra acepción, más reciente y amplia, ha sido planteada por Trevor Curnow (2004), quien la refiere a cualquier lugar donde las personas acuden para tener o entablar algún tipo de contacto con lo sobrenatural. 
Para su abordaje en el mundo andino, Curatola (2011: 9) sintetiza diferentes registros y la define o caracteriza como una institución político-religiosa conformada por un lugar sagrado tradicional, un dios que allí mora y una corporación sacerdotal que rige el organismo y tiene la facultad de entrar en contacto con dicho ser sobrenatural y hablar en nombre de él. Es decir, para sus estudios, el autor alude a dimensiones clásicas del mundo antiguo que pueden hacerse extensivas a complejas sociedades andinas prehispánicas (Curatola 2011). A nuestro entender, ciertas características que sintetiza pueden estar presentes en sociedades tradicionalmente consideradas menos complejas, en tanto cuenten con instituciones político-religiosas y donde el espacio sagrado pueda ser un lugar estático y a su vez portable o corporalmente construido de fuerza vital, conducida por especialistas que interactúan con otra dimensión o plano del mundo natural y espiritual. En este caso, considero que las descripciones etnohistóricas y actuales pueden ser parte de esta categoría heterogénea del fenómeno (sensu Curatola 2011).

\section{En la sociedad mapuche histórica y actual}

Existen registros etnohistóricos sobre la posesión de amuletos y talismanes utilizados por las y los machis y longkos (shamanes y líderes político-religiosos) para preservarse de fuerzas maléficas con las que pueden interactuar a partir de las prácticas rituales (Foerster 1985, Schindler \& Schindler-Yáñez 2006). En representación de un colectivo que incluye antropólogos, representantes sociales, políticos y espirituales de la comunidad mapuche de Cañete (Provincia de Arauco, Región del Biobío), André Menard los llama newenke kura o "piedras de poder" (2018: 2). Integrando información actualística (etnohistórica y tradición oral) las hace extensivas a ambas vertientes de la cordillera de los Andes (centro-sur de Chile y Provincia de Neuquén). Distingue dos grupos de acuerdo a su capacidad de movilidad (A y B) y describe cuatro formas de representación física (1 a 4) de piedras de poder y de su relación política y simbólica en el mundo mapuche: A) no transportables: 1) piedras santas o futa kura y piedras tacitas, que sean objeto de veneración o formen parte de relatos míticos, y B) transportables o móviles: grupo en el que distingue 2) klavas y toki $k u r a$, de funciones políticas o atribuciones de mando, las katan kura o piedras horadadas y las pinuntue con propiedades técnicas y mágicas; 3 ) piedras dotadas de personalidad o de potencias mágico-espirituales, identificadas como espíritus; y 4) piedras chamánicas, entre ellas likan y llankas -curativas y componentes del kultrün, respectivamente-.

Sobre el carácter de newen y mongen que compila y sintetiza Menard (2018), existen tres posturas principales: 1) las que enfatizan el valor espiritual, social y simbólico que las piedras vehicularían, habitadas por espíritus de antepasados cuyo poder no está en la piedra misma sino en su vida en el más allá (numinoso); 2) las que destacan la vida social y cultural de las piedras inspiradas en el animismo de Descola (2005), el perspectivismo de Viveiros de Castro (1998) y las teorías del actor-red de Latour (2005); 3) y, finalmente, las que resaltan su vitalidad o carácter extraordinario, político o carismático frente a otros objetos (totemismo).

El mismo colectivo señalado anteriormente analizó las colecciones arqueológicas y etnográficas del Museo Mapuche de Cañete, distinguiendo cinco tipos de artefactos móviles compuestos de rocas: 1) kachal kura o hachas de piedra, 2) toki kura o hachas insignia, 3) klavas, 4) figuras antropomorfas y 5) piedras de uso o de denominación enigmática (Menard 2018: 6). En suma, esta tipología solo abarca los elementos en exhibición en el museo, pero como toda tipología es una clasificación abierta y aditiva, incorporamos artefactos y ecofactos como las pu kuras (Cañas 1909) -obtenidos de ríos y seleccionados por presentar cierta forma que emula dualidad-, y estructuras -entre las que incluimos las distintas representaciones de "descansos" (Rojas et al. 2011, Skewes \& Guerra 2016), las piedras santas (Oyarzún 1924) y piedras tacitas (Menard 2018), y los kuel (Dillehay 2011)-. Queremos incluir también un grupo de artefactos y ecofactos que describiremos a continuación, identificados en el sector oriental cordillerano como "piedras imanes" o "piedras sagradas".

\section{METODOLOGÍA}

Como antecedente, contamos con los avances de Mariano Bonomo en busca de indicadores de actividad ritual en contextos arqueológicos de cazadores recolectores, más otros realizados en las regiones pampeana (Flegenheimer \& Bayón 1991), patagónica (Hermo 2008) y más recientemente araucana (Peñaloza et al. 2019, 


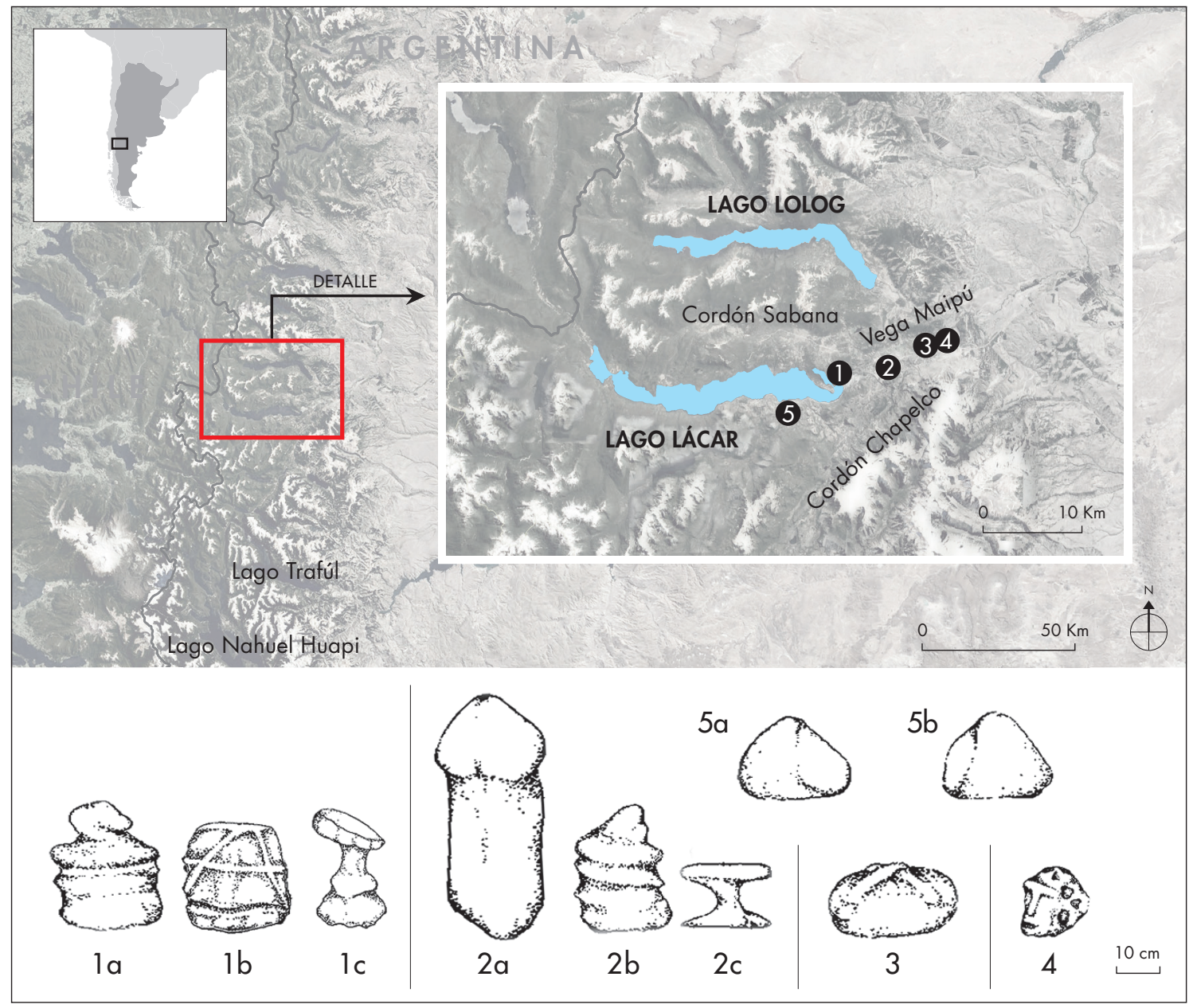

Figura 1. Ubicación e ilustración de las piedras imágenes. Figure 1. Location and illustration of the image stones.

Tabla 1. Artefactos: Pc: picado; Ab: abrasión; Pd: pulido; As: alisado. Medidas: alto y ancho máximos expresados en centímetros. Table 1. Artifacts: Pc: chipped; Ab: abrasion; Pd:polished; As: smoothing. Measurements: maximum height and width in centimeters.

\begin{tabular}{|c|c|c|c|c|c|c|}
\hline \multicolumn{2}{|c|}{ MUESTRA } & SITIO & COORDENADAS & MEDIDAS & MODIFICACIONES & MATERIA PRIMA \\
\hline \multirow{3}{*}{1} & $\mathrm{a}$ & \multirow{3}{*}{ Casa Koessler } & \multirow{3}{*}{$40^{\circ} 09^{\prime} 18^{\prime \prime} \mathrm{S}-71^{\circ} 20^{\prime} 39^{\prime \prime} \mathrm{O}$} & $45 \times 63$ & Ecofacto & Granito \\
\hline & $\mathrm{b}$ & & & $43 \times 40$ & Ecofacto & Granito \\
\hline & c & & & $41 \times 38$ & Ecofacto & Granito \\
\hline \multirow{3}{*}{2} & $\mathrm{a}$ & \multirow{3}{*}{ Los Radales 1} & \multirow{3}{*}{$40^{\circ} 09^{\prime} 32^{\prime \prime} \mathrm{S}-71^{\circ} 18^{\prime} 44^{\prime \prime} \mathrm{O}$} & $181 \times 55$ & Pc- Ab- Pd & Granito \\
\hline & $\mathrm{b}$ & & & $43 \times 50$ & Ecofacto & Granito \\
\hline & c & & & $40 \times 36$ & Ecofacto & Granito \\
\hline \multicolumn{2}{|l|}{3} & El Cañadón & $40^{\circ} 07^{\prime} 44^{\prime \prime} \mathrm{S}-71^{\circ} 13^{\prime} 50^{\prime \prime} \mathrm{O}$ & $30 \times 50$ & Ecofacto & Granito \\
\hline \multicolumn{2}{|l|}{4} & Siete Manzanos & $40^{\circ} 09^{\prime} 32^{\prime \prime} \mathrm{S}-71^{\circ} 18^{\prime} 44^{\prime \prime} \mathrm{O}$ & $58 \times 41$ & Pc- As- Pd & Granito \\
\hline \multirow[b]{2}{*}{5} & $\mathrm{a}$ & \multirow[b]{2}{*}{ Rewe } & \multirow{2}{*}{$40^{\circ} 10^{\prime} 34^{\prime \prime} \mathrm{S}-71^{\circ} 26^{\prime} 03^{\prime \prime} \mathrm{O}$} & $42 \times 43$ & Ecofacto & Granito \\
\hline & $\mathrm{b}$ & & & $44 \times 46$ & Ecofacto & Granito \\
\hline
\end{tabular}


Campbell et al. 2020), que han enfatizado variables no económicas -como la selección de materias primas por color- $y$ han postulado el uso ritual de algunos atributos del arte y rocas.

El presente estudio se centra en algunos elementos referidos a la organización tecnológica en el sentido que plantea Margaret Nelson (1991), pero siguiendo los trabajos paradigmáticos de Tacön (1991) desarrollados en sociedades cazadoras recolectoras del norte de Australia. Es decir, intenta explorarlos desde una perspectiva simbólica sobre la base de información actualística usando fuentes etnohistóricas y la etnoarqueología, sin enfatizar lo económico.

\section{ARTEFACTOS Y ECOFACTOS ARQUEOLÓGICOS}

\section{Casa Koessler}

El oráculo Koessler-Ilg es una estructura compuesta por tres ecofactos o rocas de granito, de superfícies morfológicamente alteradas por acción glaciar (abrasión y estrías negativas y positivas). Estas rocas, seleccionadas por sus cualidades externas naturales, fueron inicialmente emplazadas en sitios ceremoniales y luego trasladadas a la residencia de la familia Koessler, ubicada ca. $40^{\circ}$ $09^{\prime} 18^{\prime \prime} \mathrm{S}-71^{\circ} 20^{\prime} 39^{\prime \prime} \mathrm{O}$, a una altitud de $661 \mathrm{msnm}$ (fig. 1, tabla 1). Según informantes, esta relocalización se dio en ocasión de los trabajos etnográficos de Bertha Koessler-Ilg, cuando optaron por incluir prácticas que requerían el uso de las piedras sagradas. Cada una funcionó como báculo o cetro de los integrantes de la ceremonia. La separación de $1 \mathrm{~m}$ de distancia unas de otras y la disposición de forma triangular o cerrada generaba un espacio interior considerado como un portal dimensional, el que a la vez protege del exterior (tanto al espacio físico como a las personas).

1a) Roca granítica. Presenta superficie pulida con estrías en relieves positivos y negativos de origen detrítico criogénico (glaciar). Tiene mayor volumen respecto de los otros dos ecofactos, con una altura de $45 \mathrm{~cm}$ y un diámetro de $63 \mathrm{~cm}$.

1b) Roca granítica. De forma cilíndrica en cuerpo, aplanada en sector inferior y superior, lo que permite utilizarla como banco. Presenta superficie con abrasión y estrías en relieves positivos de origen glaciar. Tiene una altura de $43 \mathrm{~cm}$ y un diámetro de $40 \mathrm{~cm}$.

1c) Roca granítica. Presenta superficie con abrasión y estrías en relieves negativos de origen glaciar. De forma irregular, de cuerpo cilíndrico de 25 a 30 $\mathrm{cm}$ de diámetro con torsión natural, y semicircular plano en sectores inferior y superior, lo cual le da estabilidad y comodidad para utilizarla como banco. Tiene una altura de $41 \mathrm{~cm}$ y un diámetro de $38 \mathrm{~cm}$.

\section{Los Radales 1}

Los Radales 1 es un sitio arqueológico caracterizado como un asentamiento residencial a cielo abierto del Período Alfarero Tardío, con presencia de cerámica bícroma rojo sobre blanco, datado en $480 \pm 60$ años AP (Pérez 2016, 2018). Sus coordenadas geográficas son $40^{\circ}$ $09^{\prime} 32^{\prime \prime} \mathrm{S}-71^{\circ} 18^{\prime} 44^{\prime \prime} \mathrm{O}$, y se emplaza en una terraza plana de altura con buena insolación, a $853 \mathrm{msnm}$ (figs. 1 y 2 , tabla 1 ).

Al sitio se adscriben tres rocas granitoides: dos son ecofactos o geofactos semienterrados que fueron relocalizados a menos de $100 \mathrm{~m}$ de distancia; el tercero es un artefacto modificado por picado y alisado, identificado por nosotros durante el trabajo de excavación, y que describimos a continuación:

2a) Se trata de un artefacto antropomorfo fálico manufacturado a partir de una roca granítica cilíndrica alargada de $181 \mathrm{~cm}$ de largo y $55 \mathrm{~cm}$ de ancho máximo, modificada mediante picado, abrasión y pulido para modelar atributos que exalten la forma fálica. Su base presenta sección cónica, por lo que estaría enterrada, conformando así una figura monolítica erguida de tipo representativa (tabla 1: 2a y fig. 2), y que caracterizamos aquí como "menhir" (García Azcárate 2000: 74, 75 y 80 , fotos 1 y 2 de la figura 1 ). Según estudios en curso de otros investigadores, cumpliría funciones calendárico-astronómicas.

2b) Se trata de una roca granitoide de $43 \mathrm{~cm}$ de largo por $50 \mathrm{~cm}$ de ancho máximo que no presenta modificaciones antrópicas, similar al ecofacto la de la casa Koessler, transportada al sitio. 


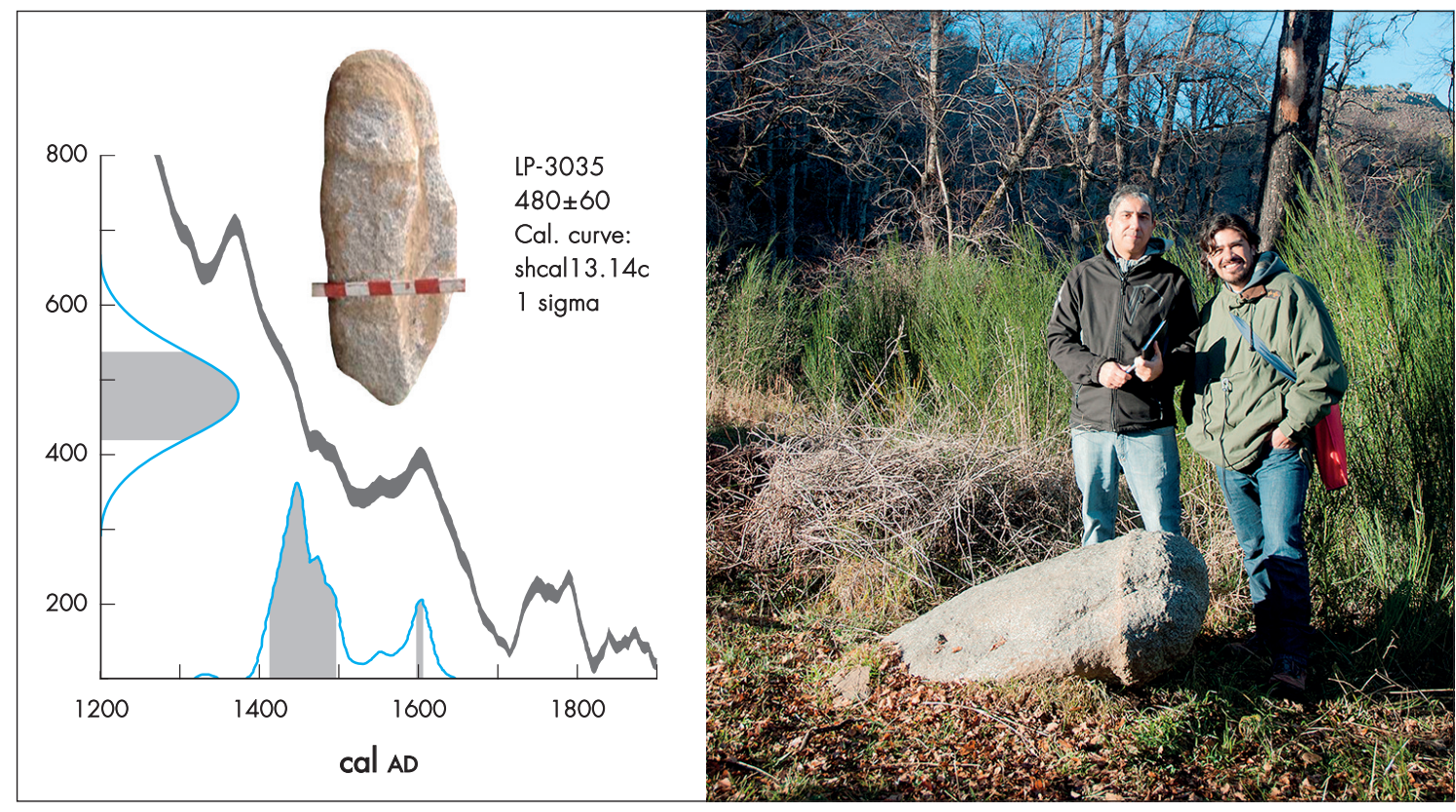

Figura 2. Cronología e imagen del menhir de Los Radales 1. Figure 2. Chronology and image of the Los Radales standing stone/menhir.

2c) Roca granitoide de $40 \mathrm{~cm}$ de alto y $36 \mathrm{~cm}$ de ancho con forma de banco, similar al ecofacto $1 c$ de la casa Koessler.

\section{El Cañadón}

Se trata de un sitio de actividades ceremoniales específicas, emplazado a cielo abierto en un sector de valle entre cañadones en la vega Maipú, en las coordenadas $40^{\circ} 07^{\prime} 44^{\prime \prime} \mathrm{S}-71^{\circ} 13^{\prime} 50^{\prime \prime} \mathrm{O}$ (figs. 1 y 3 , tabla 1 ). En el espacio ceremonial se destaca una roca monolítica granítica que identificamos como estela o "piedra imán". Su forma es semicircular, plana, de $30 \mathrm{~cm}$ de alto por 50 $\mathrm{cm}$ de ancho, con dos líneas rectas en relieve positivo en forma cruzada, similar al kultrün de la cosmología mapuche. Se trata de un ecofacto, ya que la regularidad de la superficie y los relieves en la roca parecen estrías producto de la acción glaciar, aunque sin dudas fue escogido por la singularidad de su forma y transportada a un espacio plano y abierto de terreno. La roca se encuentra aislada junto a un cuerpo de agua o arroyo, y en el único sector donde existe un parche de maitenes (Maytenus boaria), árbol sagrado que, acompañado de varas de caña colihue (Chusquea culeou), cumple la función de rewe en todos los nguillatue de la cuenca Lácar. Según Moulian \& Espinosa (2014: 646), Skewes
(2015) y Skewes \& Guerra (2016), cuevas, rocas, árboles o fuentes de agua y sus emplazamientos son concebidos como portales que conectan y dan acceso a otros estratos del universo. La trilogía agua, maitén y estela o báculo permite identificar este sector del paisaje como un rewe o espacio ritual ceremonial, donde se practicarían ceremonias incluso en épocas históricas.

\section{Siete Manzanos}

El sitio Siete Manzanos está ubicado en un sector elevado de la vega Maipú y el cordón Chapelco. Sus coordenadas son $40^{\circ} 08^{\prime} 14^{\prime \prime} \mathrm{S}-71^{\circ} 13^{\prime} 45^{\prime \prime} \mathrm{O}$, y su altitud es de $898 \mathrm{msnm}$ (figs. 1 y 4 , tabla 1 ). Se trata de un sitio a cielo abierto de características habitacionales y funerarias con artefactos cerámicos y líticos asignados al Período Alfarero Temprano (Pérez 2016, Pérez et al. 2019), datado mediante $C^{14}$ en $850 \pm 60$ años AP (LP 3271, hueso). De manera sub-superficial se identificó una roca granitoide manufacturada por picado, abrasión y pulido (en algunos sectores conformando una cara dorsal y otra ventral). La cara dorsal presenta la morfología de un rostro y tres cráneos antropomorfos dispuestos de forma multidireccional (fig. 4). Se asemeja a las esculturas modeladas de la región centro-sur de Chile, denominadas kollones, por mostrar atributos de 


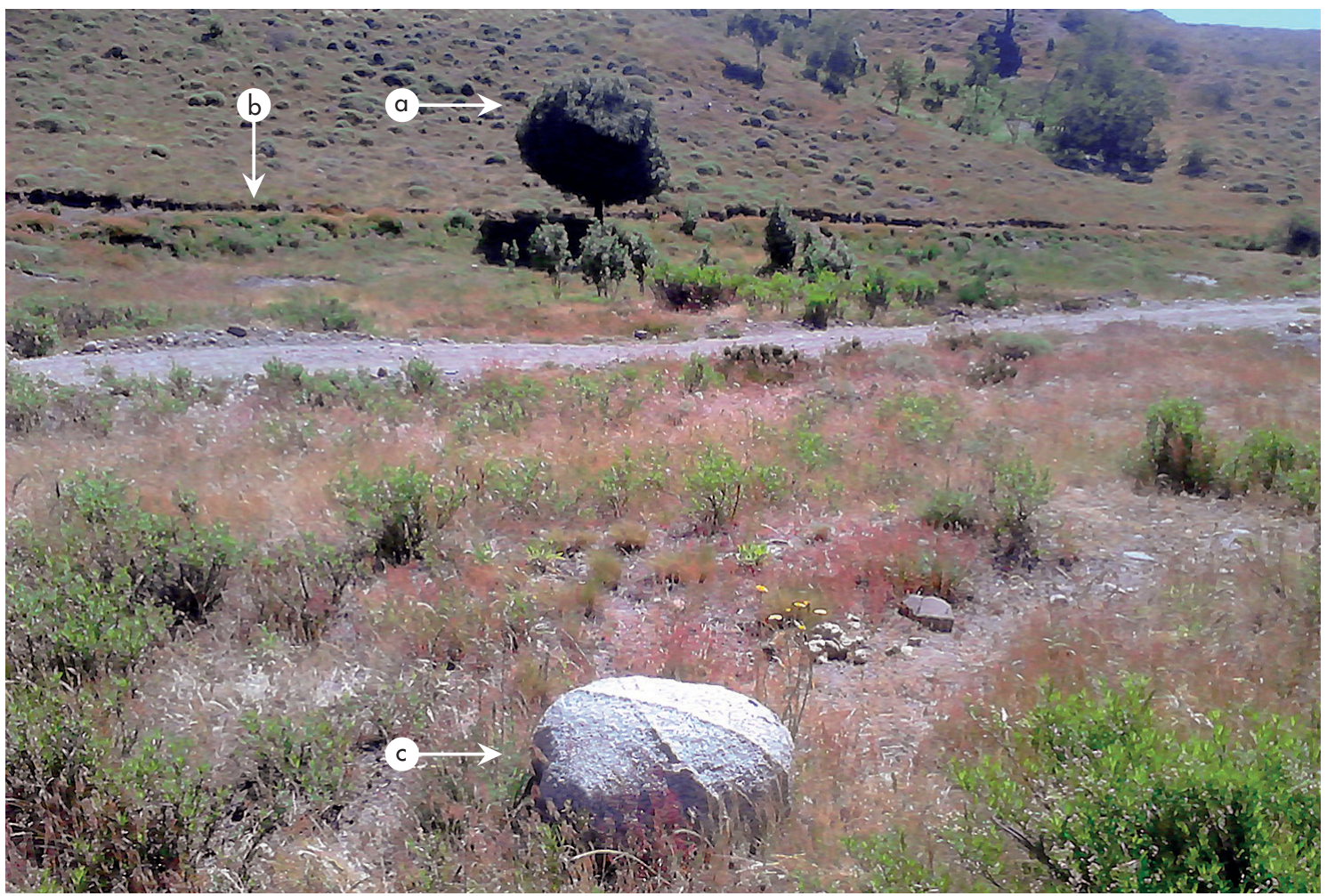

Figura 3. Sitio El Cañadón: a) maitén o árbol sagrado; b) vertiente/arroyo; c) ecofacto/estela. Figure 3. Site El Cañadón: a) maitén or sacred tree; $\boldsymbol{b}$ ) watershed/stream; $\boldsymbol{c}$ ) ecofact/trail.

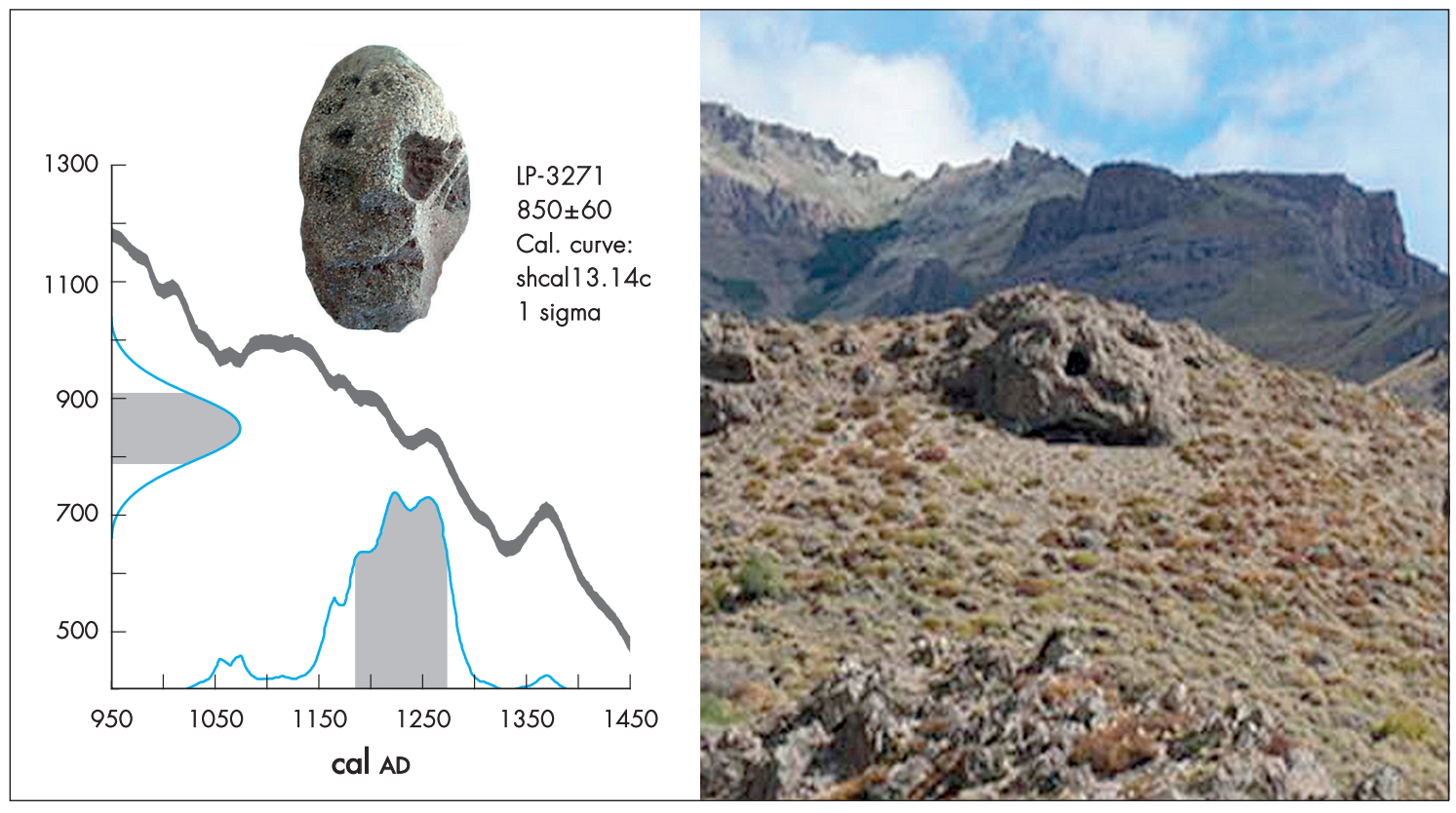

Figura 4. Kollón y sitio Siete Manzanos. A la derecha, detalle del alero rocoso con forma de calavera. Figure 4. Kollon and Siete Manzanos site. On the right side, detail of the rocky eaves in the shape of a skull. 


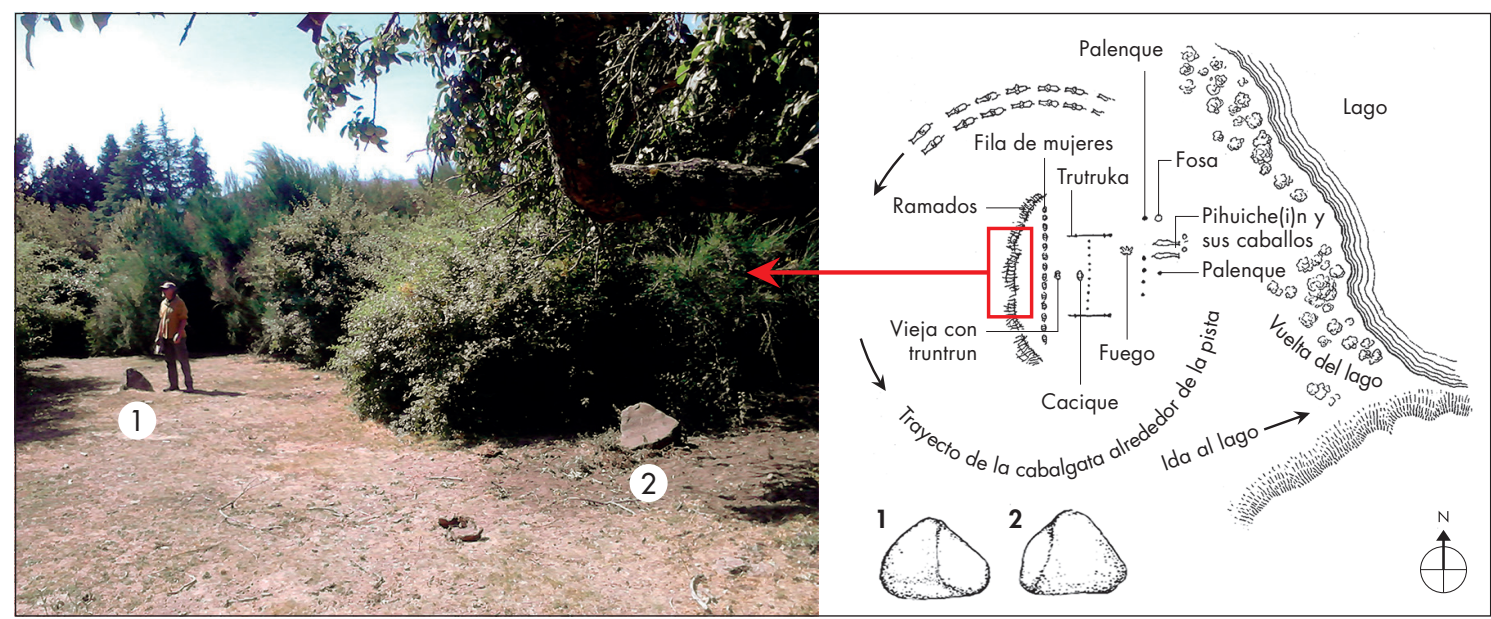

Figura 5. Sitio Rewe y plano de Gröeber \& Palavecino (1928: 295, figura 4). Figure 5. Rewe site and Gröeber \& Palavecino’s map (1928: 295, figure 4).

rostros humanos, aunque no se trata de una máscara propiamente tal, sino de una escultura monolítica que representaría o asemeja una máscara antropomorfa. Se encuentra emplazado en un sector descrito hacia el año 1862 como parte de las chacras o campos de cultivo de los hermanos Antinao y Coña, lugar que para el expedicionario Guillermo Cox constituye un hito que permite materializar la territorialidad ancestral del linaje familiar (Cox 1999 [1862-1863], Pérez 2015). De este modo, la escultura opera como hito asociado a un elemento geológico evidente conocido como "alero Calavera" (fig. 4), interpretado por los pobladores locales mapuches como un gigante petrificado, a partir de nütran o relatos de ancestralización (sensu Moulian \& Espinosa 2014). La escultura es una representación portable de esta geoforma y ambas actúan como espíritus tutelares del paisaje (Moulian \& Espinosa 2014).

\section{Rewe}

El sitio Rewe es un espacio ceremonial sobre la costa sur del lago Lácar, ubicado en la península de Quila Quina, en las coordenadas $40^{\circ} 10^{\prime} 34^{\prime \prime} \mathrm{S}-71^{\circ} 26^{\prime} 03^{\prime \prime}$ $\mathrm{O}$, y a $655 \mathrm{msnm}$ (figs. 1 y 5 , tabla 1 ). Fue visitado por el geógrafo Gröeber durante un Nguillatun en 1920 y luego descrito por él mismo (Pérez 2016). Se trata entonces de un sitio arqueológico histórico que cuenta con información etnográfica, fotografías, cartografía y planos que permiten vincular algunos ecofactos y estructuras a contextos ceremoniales como nguillatue o lugar donde se realiza nguillatun (Gröeber \& Palavecino 1928). En este caso se trata de rocas graníticas de formas geométricas (pseudopiramidales) sin atributos de modificación artificial, las cuales fueron seleccionadas y transportadas al lugar ceremonial y colocadas a intervalos considerando la disposición de áreas de actividad ritual. Según el plano que Gröeber y Palavecino realizaron del lugar durante el evento, la disposición de los ecofactos corresponde a las divisiones de recintos que ocupa cada unidad familiar del clan durante la ceremonia (Gröeber \& Palavecino 1928). Junto a los mismos se encuentra en superficie escaso material lítico y abundante cerámica (Pérez 2016). La importancia etnográfica de este sitio radica en que permite identificar ecofactos en contextos arqueológicos y hacer interpretaciones sobre su contexto sistémico (Schiffer 1976).

\section{ANÁLISIS DE LA INFORMACIÓN ETNOGRÁFICA}

\section{Federico Koessler, 2008 y 2016}

Federico Koessler es bisnieto de Bertha Koessler-Ilg y copropietario de la residencia Koessler, ubicada en San Martín de los Andes, Neuquén. En un primer encuentro en marzo de 2008 comentó -y nos mostró- que, según relatos de su abuela y otros familiares, tres rocas emplazadas en el jardín de la propiedad fueron trasladadas desde distintos espacios sagrados por algunos de los 

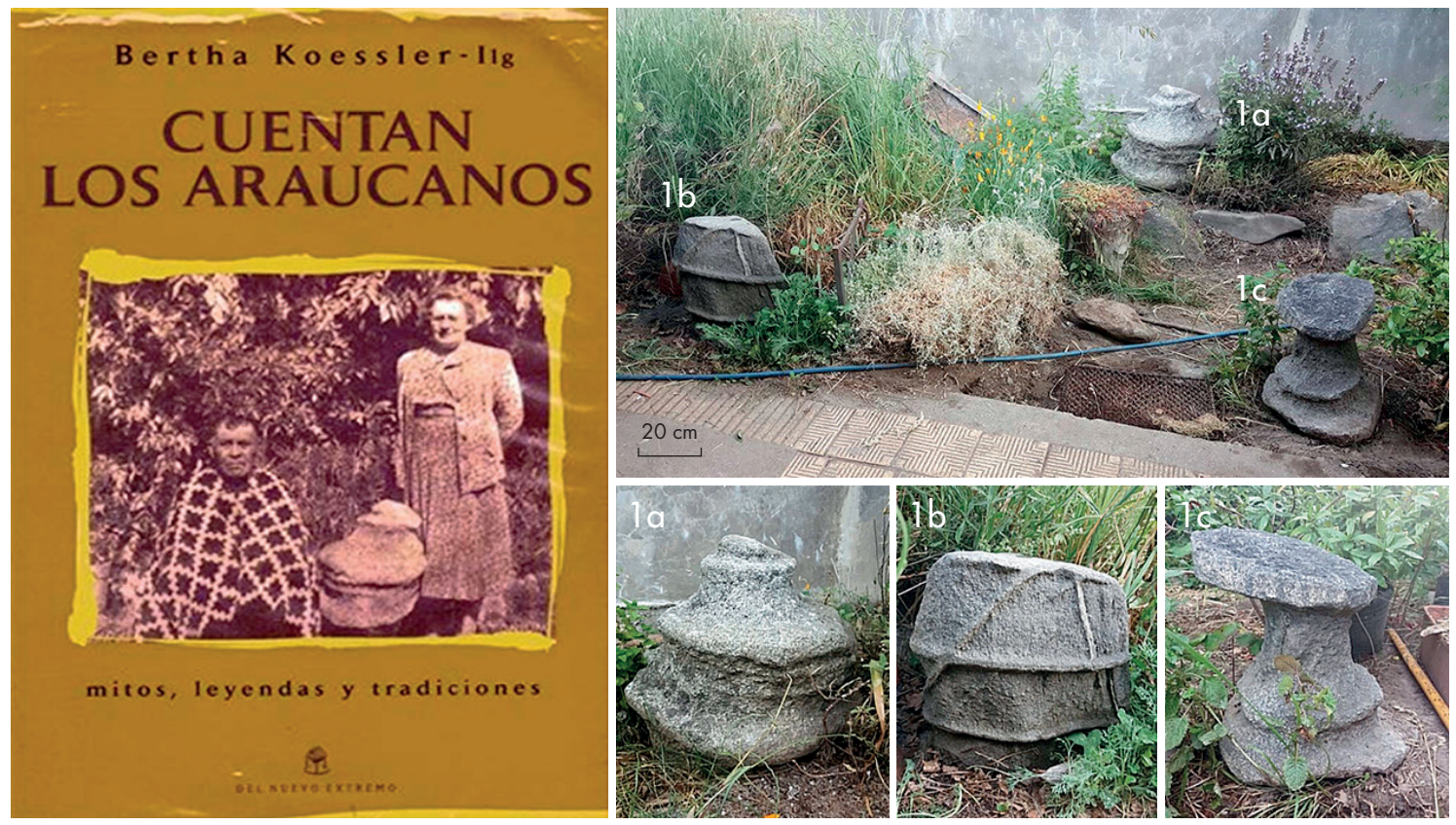

Figura 6. Relocalización del oráculo de la casa Koessler, piedras imanes 1a-c. Ver también figuras 1 y 2. Figure 6. Relocation of the oracle of the Koessler house, 1 a-c magnet stones. See also figures 1 and 2.

principales líderes político-religiosos mapuches que, durante años, colaboraron como informantes y traductores de Bertha Koessler-Ilg. El traslado de las rocas era necesario, ya que debían utilizarlas durante la invocación o transferencia de información considerada peligrosa para los participantes. Koessler afirma específicamente que la narración o canto, como forma de materialización de ciertas prácticas donde interactúan las personas con dotes especiales con entidades como ancestros o figuras míticas, debe ser realizada utilizando estas piedras. Cada individuo (especialista) tiene su propia piedra, la que, al mismo tiempo, lo protege mientras estas actúan como oráculos durante la ceremonia. A continuación, Federico Koessler nos refirió la importancia de una de las rocas a partir de la figura que ilustra la contraportada del libro Cuentan los araucanos. En ella, Bertha Koessler-Ilg y el longko Abel Curruhuinca posan junto a la piedra sagrada del último, ya depositada en el jardín de su casa antes de la década de 1960 (Koessler-Ilg 2000; fig. 6).

En noviembre de 2016, Federico Koessler agrega a la información que había dado previamente, que la disposición separada y triangular de las rocas es intencional. Esta alude a la conformación de un espacio -dentro-fuera- que actúa como campo energético que santifica el lugar donde se han desarrollado estas prác- ticas sagradas y protege a las personas de potenciales energías negativas residuales.

\section{Don Chimango, 2013 y 2016}

En el año 2013, un poblador de origen mapuche -cuyo nombre prefiere mantener en reserva y ser más bien referido por el seudónimo de Chimango- residente del barrio Los Radales y que se desempeña como cuidador del predio que limita con el sitio arqueológico Los Radales 1 , nos comenta que trasladó una "roca sagrada" que se encontraba en el lugar donde estábamos trabajando -en las cercanías del artefacto que identificamos en este trabajo como "menhir" - hasta el patio de su domicilio, a unos $30 \mathrm{~m}$ de distancia. Chimango insistió en mostrarnos la roca, la que, señaló, se trataba de una criatura sobrenatural, específicamente un ave mítica petrificada (fig. 7). La razón para el traslado de la roca hasta el lugar actual fue para proteger a los residentes de la casa de las energías negativas emanadas por los antiguos. Observamos que la roca es similar en materia prima, morfología y tamaño que la roca 1a del oráculo de Koessler (fig. 6).

En ambos relatos se advierte que las piedras de granito funcionan como herramientas para interactuar con una dimensión sobrenatural, es decir, forman parte 


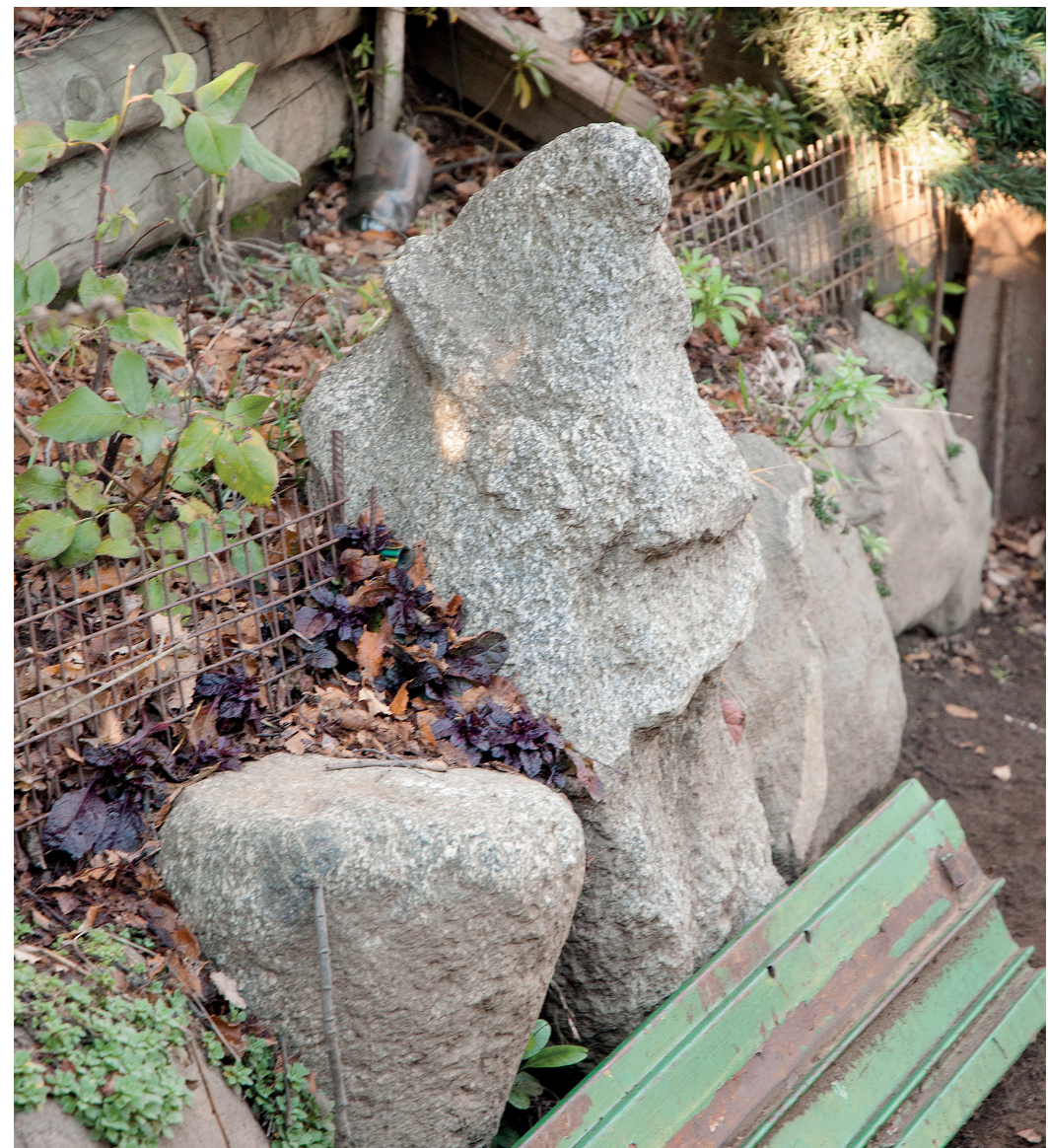

Figura 7. Imágenes de la roca ornitomorfa, según informante. Ver detalles en figuras 1, 2-b y tabla 1, 2-b. Figure 7. Pictures of the ornithomorphic stone according to informant. See details in figures 1, 2-b and table 1, $2 b$. de los elementos componentes que operan como un portal en espacios de transmisión de información y consultas u oráculos. El acto mismo de la ceremonia implica que, durante el lapso en que ese portal entre el mundo terrenal y espiritual es abierto, el equilibro natural es alterado y energías/fuerzas pueden ingresar a través del mismo y afectar el mundo terrenal (catastrofismos ambientales) y a las personas (mala suerte, enfermedad, muerte, etc.). En todo caso, las rocas cumplen la doble función de oráculo y talismán.

\section{DISCUSIÓN}

En la cuenca Lácar, el granito, como materia prima predominante entre estos artefactos y ecofactos, se encuentra en forma natural como bloques o detritos y guijarros en morrenas y arroyos cercanos a los sitios arqueológicos descritos.
La denominación "piedra imán" alude a propiedades magnéticas que no hemos podido corroborar mediante pruebas sutiles, como la alteración de la aguja de una brújula manual o el uso de magnetómetro electrónico de mayor resolución. Entonces, ¿por qué se las llama piedras imanes? Aquí podemos encontrar una vinculación entre la materia prima (granito), a partir de su alto contenido de cuarzo, y ciertas propiedades inherentes al mismo, como la generación de electromagnetismo inducido por fenómenos naturales, como la presión producida durante terremotos. La presión también puede ser inducida artificialmente y se la conoce como piezoelectricidad. Recordemos que la cuenca Lácar es un área sísmica como el resto de la cordillera y que, como parte de la cuenca valdiviana, ha experimentado el terremoto de mayor escala conocido en el planeta.

Según el Centro de Sismología Nacional de la Universidad de Chile (CSN), se registran anualmente más de 200 sismos en la región, aunque la mayoría son 
imperceptibles para nuestros sentidos. Sin embargo, sabemos que la presión ejercida durante sismos en paisajes graníticos, como los que abundan en la cuenca Lácar (Fidalgo \& Porro 1978, Flint \& Fidalgo 1964, Ferrer 1982), puede producir energía electromagnética como fenómenos reversibles de corta duración. Durante estos episodios, las formaciones graníticas pueden generar atracción magnética e incluso haces de luz similares a centellas en la atmósfera. En suma, estos fenómenos físicos que se producen en la naturaleza pudieron ser observados y agregar un valor simbólico al paisaje de la zona, incluso tomando rocas entre los detritos de depósitos glacifluviales para su utilización ritual a partir de la litificación (sensu Moulian \& Espinosa 2014) de entidades sobrenaturales atribuidas a las mismas por su forma y ciertas cualidades inherentes a la materia prima y su contexto ambiental.

En la vertiente cordillerana occidental de la Región de La Araucanía, en el valle de Lumaco, se encuentran rocas con alto contenido de cuarzo que, según informantes locales, refractan su energía o fuerza vital iluminándose y generando haces de luz de color azulado. Estas rocas son utilizadas como hito-oráculos, señal luminosa para la circulación y también para predecir eventos físicos naturales (Rosamel Millaman, com. pers., 2019). La frecuencia o grado de recurrencia de eventos sísmicos en la zona puede determinar que un observador adquiera la habilidad de predecir fenómenos naturales -los mismos sismos, por ejemplo- transformándose en oráculos, tanto la roca, como los especialistas que interpretan las señales.

\section{CONSIDERACIONES FINALES}

El culto a espíritus ancestrales emplazados en el paisaje es uno de los componentes distintivos de la religiosidad mapuche comprendida en la bibliografía etnográfica bajo el concepto de "mediadores" (Foerster 1993, Foerster \& Gunderman 1996). Se trata de espíritus personificados que actúan como intercesores ante las deidades (Moulian \& Espinosa 2014: 638). Observamos que estos espacios sagrados pueden ser geoformas naturales (Skewes \& Guerra 2016, Menard 2018), pero el registro etnográfico sugiere también que pueden operar de la misma forma estructuras artificiales, como el oráculo de la casa Koessler, así como cualquier otra estructura caracterizada como nguillatue o también rewe.
Entre las piedras imanes etnográficas de la cuenca Lácar se incluyen artefactos, ecofactos y estructuras. Los ecofactos son los más utilizados, fruto de la selección de rocas con formas singulares y tamaños adecuados para ser transportados a un espacio ceremonial-habitacional. En este sentido, notamos una similitud que permite integrar las observaciones del sector oriental cordillerano con los registros orientales descritos por Menard (2018: 2) bajo la categoría de newenke kura o piedras de poder. Esta categoría integra toda la variedad de lo consignado como no transportable (estructuras, formaciones rocosas y paisajes), así como aquello transportable o móvil (artefactos y ecofactos), descrito en el presente trabajo.

Las rocas observadas en los sitios arqueológicos Rewe, Los Radales 1, El Cañadón y Siete Manzanos comparten las siguientes características con las piedras imanes etnográficas: son artefactos y ecofactos de morfología zoomorfa y antropomorfa representativa, y otros con atributos abstractos (estrías geométricas en relieve positivo) de origen natural, principalmente inducidas por acción glaciar. Estos artefactos y ecofactos no están vinculados directamente a actividades de subsistencia. Son móviles, aunque poco transportables por su tamaño y peso, con un tamaño promedio de $45 \mathrm{~cm}$ de altura y $43 \mathrm{~cm}$ de ancho (90\% de la muestra, sin contemplar el menhir). No obstante, observamos que el factor peso es el que los hace menos transportables (15 kg el más liviano, muestra $2 c$, fig. 1). La variable tamaño/peso puede ser una propiedad que incide en la selectividad de la materia prima.

Otras rocas de la misma composición granítica y origen glaciar han sido modificadas por picado, abrasión y pulido para exaltar atributos antropomorfos pero considerados inherentes a la roca, como la morfología fálica en el caso de Los Radales 1 y la geometría en el caso de la máscara-escultura de Siete Manzanos, que ofrece soportes o "caras" múltidireccionales.

En suma, el registro etnohistórico y etnográfico nos permite, en primer lugar y al menos a nivel de hipótesis, otorgar a estas rocas graníticas de presencia recurrente en sitios arqueológicos de la cuenca Lácar, la categoría de artefactos y ecofactos arqueológicos. En segundo lugar, la vinculación etnohistórica y etnográfica de similares artefactos durante el siglo xx en el área de estudio, con el uso y función en distintas prácticas rituales -al igual que las newenke kura- y toda la variabilidad descrita para el sector occidental cordillerano, 
posibilita identificar sectores específicos del espacio, dentro de los sitios arqueológicos, como potenciales áreas de uso ceremonial.

Respecto de la antigüedad de las prácticas que involucran elementos no transportables - paisajes, geoformas (naturales) y estructuras (artificiales)- y transportables -artefactos y ecofactos-, podemos proponer una proyección temporal en el uso diacrónico del sitio Siete Manzanos como lugar de importancia simbólica asociada tanto a geoformas naturales que representan ancestros o criaturas míticas (alero Calavera) como a artefactos graníticos (kollon de granito). Estos últimos, funcionan, además, como hito y son elementos que podemos adscribir a la categoría de newenke kura o piedras de poder (sensu Menard 2018: 2).

Según datos etnohistóricos, este espacio sacralizado y los elementos que lo componen visibilizan y materializan la territorialidad del linaje que lo habitaba hacia la década de 1860 (Cox 1999 [1862-1863]). Además, el mismo lugar fue utilizado como espacio formal de entierros humanos (Pérez et al. 2019) durante momentos finales o tardíos del Período Alfarero Temprano de la secuencia regional (Pérez 2016), datado en 850 \pm 60 años AP en el sitio Siete Manzanos (Pérez et al. 2019). Asimismo, podemos observar las dataciones de Los Radales 1, cuyos monolitos graníticos están asociados a artefactos característicos de etapas finales del Período Alfarero Tardío (cerámica de la tradición bícroma rojo sobre blanco), y datado en $480 \pm 60$ años AP (Pérez 2018). A su vez, tanto el sitio Rewe en la península de Quila Quina como la casa Koessler sugieren la continuidad de las prácticas rituales que involucran piedras imanes o piedras de poder (sensu Menard 2018) hacia la primera mitad del siglo xx. A principios de la década de 1960, los relatos de Gregorio Curruhuinca compilados por Hassler (1963) muestran que en la cuenca Lácar estas habían dejado de utilizarse en las prácticas ceremoniales.

Finalmente, como resultado de este trabajo y luego de más de sesenta años, la comunidad mapuche de la cuenca Lácar volvió a conocer el paradero de estos artefactos de gran valor simbólico. Actualmente dialoga con la familia Koessler y con distintos estamentos políticoreligiosos mapuches para la recuperación y eventual traslado de los mismos, con el desafío de recuperar la funcionalidad que cumplen individualmente, sin perder la que también tuvieron durante las últimas décadas como estructura conjunta.
Agradecimientos Al licenciado Rosamel Millaman por la información aportada sobre Lumaco. A los señores Koessler y Chimango por sus valiosos comentarios. A Ariel Epulef, ex longko de la Comunidad Mapuche Curruhuinca, por su constante apoyo. A los evaluadores anónimos, cuyos comentarios y recomendaciones contribuyeron a mejorar el trabajo.

\section{REFERENCIAS}

Álvarez, G. 1984. Donde estuvo el paraíso. Del Tronador a Copahue. Neuquén: Siringa Libros.

BouChÉ-LeClerCQ, A. 1963 [1879-1882]. Histoire de la divination dans l'Antiquité. Brussels: Culture et Civilisation.

Bonomo, M. 2006. Un acercamiento a la dimensión simbólica de la cultura material en la región pampeana. Relaciones de la Sociedad Argentina de Antropología xxxi: 89-116.

Campbell, R., Moya Cañoles, F. \& Gutiérrez, R. 2020. Quien busca, encuentra. Arte rupestre en el sur de Chile: evaluación, perspectivas y preguntas. Boletín del Museo Chileno de Arte Precolombino 25 (1): 247-269.

CAÑAs, A. 1909. El culto a la piedra en Chile y en otras partes del mundo. Santiago: Imprenta Cervantes.

Cox, G. 1999 [1862-1863]. Viaje a las rejiones septentrionales de la Patagonia. Buenos Aires: Elefante Blanco.

Curatola Petrocchi, M. 2011. ¿Fueron Pachacamac y los otros grandes santuarios del mundo andino antiguo verdaderos oráculos? Diálogo Andino 3: 5-19.

Curatola Petrocchi, M. \& Ziólkowski, M. S. (Eds.) 2008. Adivinación y oráculos en el mundo andino antiguo. Lima: Pontificia Universidad Católica del Perú-Instituto Francés de Estudios Andinos.

Curnow, T. 2004. The oracles of the Ancient World. London: Duckworth.

Descola, P. 2005. Par-delà nature et culture. Paris: Gallimard.

Dillehay, T. 2011. Monumentos, imperios y resistencia en los Andes. San Pedro de Atacama: Universidad Católica del Norte.

Duviols, P. 1973. Un symbolisme andin du doble: la lithomorphose de l'ancestre. In Actes de XVII Congrès International des Américanistes, vol. vi, pp. 359-364. Paris: Société des américanistes de Paris.

FARon, L. 1997. Antupainamko. Moral y ritual mapuche. Santiago: Mundo.

Ferrer, J. 1982. Geología (recopilación para estudio regional de suelos), carta 1:500.000. In Consejo Federal de Inversiones (CFI), 1982. Relevamiento y priorización de áreas con posibilidades de riesgo. Buenos Aires: SEgemar.

Fidalgo, F. \& Porro, N. 1978. Geología glacial. Geología y recursos naturales del Neuquén. VII Congreso Geológico Argentino, pp. 129-136. Neuquén: Asociación Geológica Argentina.

Flegenheimer, N. \& BAyón, C. 1999. Abastecimiento de rocas en sitios pampeanos tempranos: recolectando colores. In 
En los tres reinos: prácticas de recolección en el cono sur de América, C. A. Aschero, M. A. Korstanje \& P. M. Vuoto, eds., pp. 95-107. Tucumán: Instituto de Arqueología y Museo-Facultad de Ciencias Naturales, Instituto Miguel Lilio, UNT.

FLINT, R. F. \& FidAlgO, F. 1964. Glacial geology of the flank of the argentine Andes between $39^{\circ} 10^{\prime}$ lat. S and $41^{\circ} 20^{\prime}$ lat. S. Geological Society American Bulletin 75 (4): 335-352.

Foerster, R. 1985. Piedra Santa: el Yumbel mapuche. Pastoral Popular 36 (4): 25-27.

Foerster, R. 1993. Introducción a la religiosidad mapuche. Santiago: Editorial Universitaria.

Foerster, R. \& Gunderman, H. 1996. Religiosidad mapuche contemporánea. Elementos introductorios. In Etnografía. Sociedades indígenas contemporáneas y su ideología, J. Hidalgo, V. Schiappacasse, C. Aldunate del S. \& P. Mege, eds., pp. 189-240. Santiago: Andrés Bello.

GAldAMES, L. 1987. Vitalidad de la piedra y petrificación de la vida: notas sobre la mentalidad andina. Diálogo Andino 6: 129-143.

García AzcÁrate, J. 2000. Símbolos, piedras y espacios: una experiencia semiológica. In Arte en las rocas. Arte rupestre, menhires y piedras de colores en Argentina, M. M. Podestá \& M. de Hoyos, eds., pp. 73-81. Buenos Aires: SAA.

Groeber, P. \& Palavecino, E. 1928. Un Nguillatum en el lago Lakar. Anales de la Sociedad Argentina de Estudios Geográficos 3 (1): 290-314.

Hassler, W. 1963. Vivo diálogo del lenguaraz con el cacique Curruhuinca. In Actas del Primer congreso del Área Araucana Argentina, vol. I, pp. 52-53. Neuquén: Provincia del Neuquén-Junta de Estudios Araucanos.

Hermo, D. 2008. Rocas como símbolos: la selección de materias primas para puntas de proyectil en ambientes mesetarios de la Patagonia. Intersecciones en Antropología 9: 319-324.

INGOLD, T. 2000. The perception of the environment. Essays in livelihood, dwelling and skill. London-New York: Routledge.

Jones, J. \& MACGregor, G. 2002. Introduction. Wonderfull things: color studies in archaeology from Munsell to materiality. In Colouring the past: the significance of colour in archaeological research, J. Andrews \& G. Mac Grover, eds., pp. 1-21. Oxford: Berg Publishers.

Koessler-Ilg, B. 1962. Tradiciones araucanas. Vol. I. La Plata: Instituto de Filología, Facultad de Humanidades y Ciencias de la Educación, Universidad Nacional de La Plata.

Koessler-ILG, B. 2000. Cuentan los araucanos. Mitos, leyendas y tradiciones. Buenos Aires: Editorial del Nuevo Extremo.

LATCHAM, R. 1924. La organización social y las creencias religiosas de los antiguos araucanos. Publicaciones del Museo de Etnología y Antropología de Chile 3: 2-4.

Latour, B. 2005. Changer de société. Refaire de la sociologie. Paris: La Découverte.

LÉvi-Strauss, C. 1982. El pensamiento salvaje. Mexico: Fondo de Cultura Económica.
Moulian, R. \& Espinosa, P. 2014. Pneumatología, paisaje y culto: patrones andinos en los procesos de ancestralización de la cultura mapuche williche emplazados en la naturaleza. Chungara 46 (4): 637-650.

MedinA, J. T. 1952 [1882]. Los aborijenes de Chile. Santiago: Imprenta Gutemberg.

Menard, A. 2018. Sobre la vida y el poder de las piedras: Newenke kura en el Museo Mapuche de Cañete. Colecciones Digitales, Subdirección de Investigación, Servicio Nacional del Patrimonio Cultural. <https://www.museomapuchecanete.gob.cl/641/articles-88746_archivo_PDF. pdf> [consultado: 22-02-2021].

Moreno, F. P. 2010 [1876]. Viaje a la Patagonia septentrional. Buenos Aires: El Elefante Blanco.

Nelson, M. 1991. The study of technological organization. Advances of archaeological method and theory 3: 57-100.

Oyarzún, A. 1924. La Piedra Santa de Retricura. Publicaciones del Museo de Etnología y Antropología de Chile Iv (1-2): 137-145.

PARke, H. W. 1967. A greek oracles. London: Hutchinson University Library.

Peñaloza, M., Campbell, R. \& Stern, C. 2019. Las puntas de obsidiana "atigrada" como bien de prestigio en poblaciones del "complejo El Vergel” en Isla Mocha, Región del Biobío (1100-1700 DC). In Arqueología de la Patagonia: el pasado en las arenas, J. Gómez Otero, A. Svoboda \& A. Banegas, eds., pp. 53-65. Puerto Madryn: Instituto de Diversidad y Evolución Austral.

Pérez, A. E. 2015. Lofche Curruhuinca. Aportes documentales para el conocimiento de su territorio y linaje. Buenos Aires: Imprenta del Senado de la Nación.

Pérez, A. E. 2016. El registro arqueológico de la cuenca binacional del río Valdivia. La integración de su fuente, el lago Lácar, sector oriental cordillerano. In AraucaníaNorpatagonia. Discursos y representaciones de la materialidad, M. A. Nicoletti \& P. Núñez, eds. pp. 144-187. Bariloche: Universidad Nacional de Río Negro.

PéReZ, A. E. 2018. Tecnología cerámica de Los Radales 1. Período Alfarero Tardío (El Vergel), sector oriental cordillerano de la cuenca valdiviana (Neuquén, Patagonia Argentina). Arqueología Iberoamericana 39: 29-35.

Pérez, A. E., Reyes Sánchez, F. \& Schuster, V. 2019. Una nueva modalidad de entierro humano directo del Período Alfarero en la cuenca valdiviana: el sitio arqueológico Siete Manzanos (Neuquén, Patagonia Argentina). Arqueología Iberoamericana 44 (3): 28-38.

RADCLIFFE-BRown, A. R. 1973. Estrutura e função na sociedade primitiva. Petrópolis: Vozes.

Rojas, P., Skewes, J. C., Poblete, P. \& Guerra, D. E. 2011. Los descansos de lago Neltume: imágenes de los hitos funerarios del mundo mapuche cordillerano. Revista Chilena de Antropología Visual 17: 124-145.

Rubina, C. 1992. La petrificación en el Manuscrito de Huarochirí. Mester 21: 71-82. 
SAUNDERs, N. 1999. Biographies of brilliance: pearls, transformation of matter and being, C. AD 1492. World Archaeology 31 (2): 243-257.

SAUnders, N. 2004. The cosmic earth. Materiality and mineralogy in the Americas. In Soils, stones and symbols. Cultural perception of the mineral world, N. Boivin \& $\mathrm{M}$. A. Owoc, eds., pp. 123-142. London: UCL Press.

SCHINDleR, H. \& SchindleR-YÁÑEZ, M. 2006. La piedra santa del río Lumaco. In Acerca de la espiritualidad mapuche, $\mathrm{H}$. Schindler, ed., pp. 11-67. Munich: Meidenbauer.

Schiffer, M. B. 1976. Behavioral archaeology. New YorkLondon: Academic Press.

SkEwes, J. C. 2015. Sobre árboles y personas: la presencia del roble en la vida cordillerana mapuche de la cuenca del río Valdivia. Atenea 512: 189-210.

Skewes, J. C. \& Guerra, D. E. 2016. Sobre árboles, volcanes y lagos: algunos giros ontológicos para comprender la geografía mapuche cordillerana del sur de Chile. Intersecciones en Antropología 17: 63-76.
TACÖN, P. S. C. 1991. The power of stone: symbolic aspects of stone use and tool development in western Arnhem Land, Australia. Antiquity 65 (247): 192-207.

TAYlor, G. 1987. Ritos y tradiciones de Huarochirí. Lima: Instituto de Estudios Peruanos.

Taylor, G. 2000. Camac, Camay, Camasca y otros ensayos sobre Huarochirí y Yauyos. Lima: Centro de Estudios Regionales Andinos Bartolomé de Las Casas-Instituto Francés de Estudios Andinos.

Treutler, P. 1958 [1859]. Andanzas de un alemán en Chile: 1851-1863. Santiago: Editorial del Pacífico.

Viveiros de Castro, E. 1998. Los pronombres cosmológicos y el perspectivismo amerindio. In Tierra adentro. Territorio indígena y percepción del mundo, A. Surralles \& P. García, eds., pp. 176-226. Copenhague: International Work Group for Indigenous Affairs. 